RESEARCH ARTICLE

\title{
Association of dietary intake and dietary habits with risk of cardiovascular disease among immigrant Pakistanis living in the Netherlands
}

\author{
Qaisar Raza, ${ }^{1}$ Mary Nicolaou, ${ }^{2}$ Funda Cay, ${ }^{3}$ Jaap Seidell4
}

\begin{abstract}
Objective: To explore the current intake/changed dietary habits being associated with risk of cardiovascular disease after migration from Pakistan to the Netherlands.

Methods: Data collection started in March 2012 and ended in July 2013. Self-administered survey with respect to cardiovascular disease and dietary intake was filled by 154 adult Pakistanis. Participants were approached through festivals and community centres. Descriptive statistics was used to analyse the data.

Results: There were 41 (61\%) participants who reported drinking fruit juice every day, while 13 (18.6\%) participants reported drinking soft drinks 5-7 days a week. In addition, 20 (30\%) participants reported decreased intake of high fat/fried foods, deserts/candy/sweets and red meat, while 23 (35\%) reported an increased intake of soft drinks and convenience foods, as far as high calorie and refined food items were considered, after migration.

Conclusion The study showed significant changes in dietary habits, both favourable and unfavourable, being associated with risk of cardiovascular diseases among immigrant Pakistanis living in The Netherlands.
\end{abstract}

Keywords: Pakistani, CVD, Migration, Diet, Dietary acculturation. (JPMA 71: 219; 2021)

DOI: https://doi.org/10.47391/JPMA.219

\section{Introduction}

Migration and acculturation are associated with risks of chronic disease patterns. ${ }^{1,2}$ Most epidemiological studies have shown that South Asians living in western countries have a higher risk of cardiovascular disease (CVD) as compared to local population.2,3 Pakistan is one of the largest countries in South Asia, with a population of 180 million. CVD accounts for $34 \%$ of all deaths in Pakistan. ${ }^{4}$ In addition, Pakistan stands 9th regarding prevalence of obesity worldwide. 5

It is worthwhile to note that diet is presumed to be a key lifestyle factor contributing to this increased risk.6,7 The traditional South Asian cuisines mainly consist of rice, wholemeal grains, meat and a variety of fruits and vegetables; fish is not part of traditional diet, but it is consumed largely in coastal areas of South Asia. In addition, cooking at home is preferred for economical and cultural reasons. After migration to western countries, though, South Asians are influenced by the food culture of local population, while they contribute to widening the spectre of existing food habits through shops and restaurants, like other migrant communities.8,9

Department of Clinical Nutrition, Nur International University, Lahore, Pakistan, 2Department of Public Health, Academic Medical Centre, University of Amsterdam, Netherlands, 3,4Department of Health Sciences, VU University Amsterdam, Netherlands.

Correspondence: Qaisar Raza. Email: qaisar.maastricht@gmail.com
Different surveys in Pakistan have shown healthy trends towards high consumption of fish and fruit, but vegetables are consumed in lesser amounts especially in urban areas, which is unhealthy. In addition, 23\% participants reported consumption of red meat daily. ${ }^{10,11}$ Traditional cooking methods include deep frying and use of pressure cooker in Pakistani cuisine. ${ }^{12}$

There is a large Pakistani diaspora living in western countries such as Norway and England. Most of the studies on dietary patterns of Pakistani immigrants have been conducted in Norway and England. A cross sectional study in Oslo among Pakistanis reported increased consumption of oil, meat, fish and potatoes and decreased consumption of beans and lentils after migration from Pakistan. ${ }^{13}$ Similarly a focus group among women of Pakistani descent in Oslo reported changes in meal pattern and meal composition. ${ }^{14}$ The response of immigrants to a particular food environment in a country determines their vulnerability to non-communicable diseases including cardiovascular diseases. Thus findings about dietary habits of Pakistanis living in Norway and UK could be similar or different from Pakistanis living in The Netherlands.

There are 18579 Pakistanis in Netherlands according to the Central bureau of statistics, The Netherlands; 10493 are males while 8086 are females. ${ }^{15}$ Pakistanis have shorter mean duration of stay in The Netherlands (20-30 years) as compared to Pakistanis living in UK and USA 
(more than 40 years). ${ }^{16}$

In The Netherlands, most of the studies pertaining to diets of immigrants have focused on Surinamese, Moroccan and Turkish immigrants due to their large presence. ${ }^{17,18}$ Approximately $80 \%$ of the Surinamese residents of The Netherlands are either of South Asian or Afro-Caribbean origin. However, there is large heterogeneity among South Asian populations regarding their disease and dietary patterns ${ }^{19}$ implying that findings regarding diet and disease risk of South Asian Surinamese are not necessarily applicable to Pakistani migrant population.

There is no earlier study exploring dietary habits of immigrant Pakistanis in The Netherlands. This leads us to ask the following explorative research questions.

Is food intake being associated with risks of cardiovascular disease among Pakistani immigrants living in The Netherlands?

How dietary habits influence such risks among them after migration?

\section{Methods}

This was a cross sectional study conducted in the Netherlands. Data collection started in March 2012 and ended in July 2013 in the Netherlands. The data was collected using questionnaire method regarding diseases, diet and other lifestyle measures. The study included adults who were 18 years or older Pakistanis living in the Netherlands. Self identification as a Pakistani met inclusion criteria of this study.

Participants were approached through festivals, mosques and Pakistani shops. The study was advertised through prayer leaders, community leaders, leaflets and posters in social media. In total, three Pakistani mosques in Amsterdam were selected for distribution of the questionnaires. There were approximately 100-150 persons in each mosque. It must be noted that they were all men. The number of questionnaires distributed in each mosque varied from 50-100. The principal researcher along with a colleague (AK) visited Pakistan embassy for 5 consecutive days in August 2013 for data collection. The researchers asked participants, who came to visit embassy, to fill in the questionnaire right at the moment. There were 23 questionnaires distributed at the embassy. Questionnaires were also distributed in Pakistani shops in Amsterdam, in different cities of The Netherlands and at Pakistani festivals. At the first occasion, participants were given questionnaires to fill in at home. However, due to poor response, at the second occasion, they were asked to fill in the questionnaire on the spot (Figure-1).
Convenient sampling was used to collect data from Pakistanis living in the Netherlands. As this was the first study to collect data from Pakistanis living in the Netherlands regarding diet and health, so an effort was made to recruit as many participants as possible. Following formula was used for sample size calculation taking into account the prevalence of cardiovascular disease among South Asians in the Netherlands (23\%) from previous studies. ${ }^{20}$

$$
\begin{gathered}
\underline{Z} \frac{\underline{2} p(1-p)}{d^{2}} \\
\frac{1.96 * 0.23(1-0.23)=271}{0.052}
\end{gathered}
$$

Thus the sample size calculation showed that this study required recruiting a minimum of 271 participants.

This study was conducted according to the guidelines laid down in the Declaration of Helsinki. The study was totally anonymous and each person was informed personally about background of the study and was asked for his/her verbal consent. According to Dutch laws and regulations for scientific approval of a study, "Verbal consent is required and is enough from those involved if the study is totally anonymous". ${ }^{21}$ We obtained exemption for ethical approval from the Medical Ethics Review Committee of VU University Medical centre.

An existing questionnaire from the Amsterdam public health service (2008 version) was modified to develop questionnaire about cardiovascular disease and dietary intake among Pakistanis living in the Netherlands. ${ }^{22}$ Pubmed search with terms as cardiovascular disease, Pakistani immigrants, food habits and a relevant food questionnaire with project title "Impact of dietary patterns on metabolic syndrome in South Asian population of the UK" was quite helpful in developing the questionnaire for the present study. ${ }^{23}$

Pretesting of the questionnaire was done before final data collection. The questionnaire took approximately 20 to 25 minutes per participant. The questionnaire was originally developed in English and then translated in Urdu (National Language of Pakistan) with the help of a Pakistani researcher. Urdu questionnaire was comparable to English questionnaire in all aspects including meaning, design and layout.

All variables used in this analysis were self-reported. BMI was calculated from height and weight. The cut-off points used for overweight and obesity regarding $\mathrm{BMI}$ were (BMI $\geq 23.0-27.5 \mathrm{Kg} / \mathrm{m}^{2}$ ) and $\left(\mathrm{BMI} \geq 27.5 \mathrm{Kg} / \mathrm{m}^{2}\right)$, respectively. In addition, general health status was measured with a 
Questionnaire Development from March-June 2012

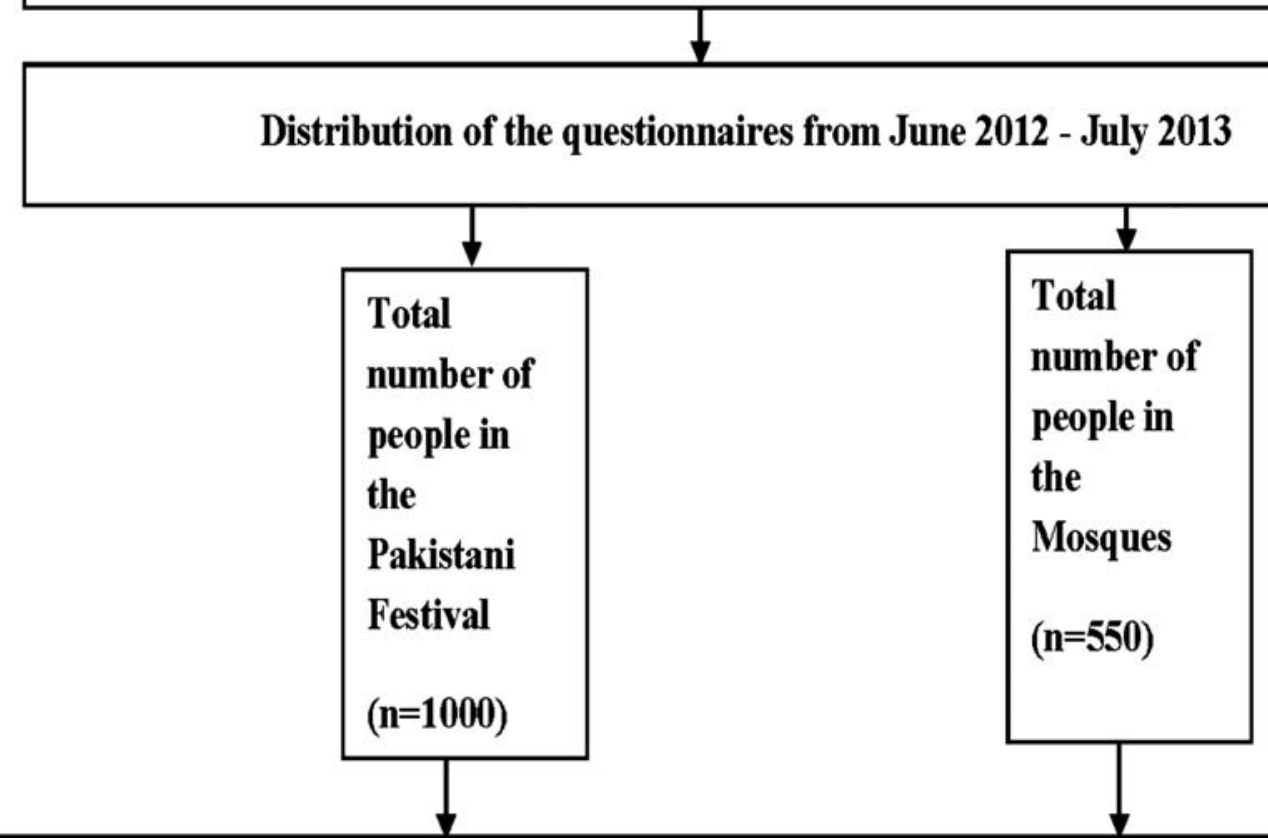

Number of Questionnaires distributed to people at different locations

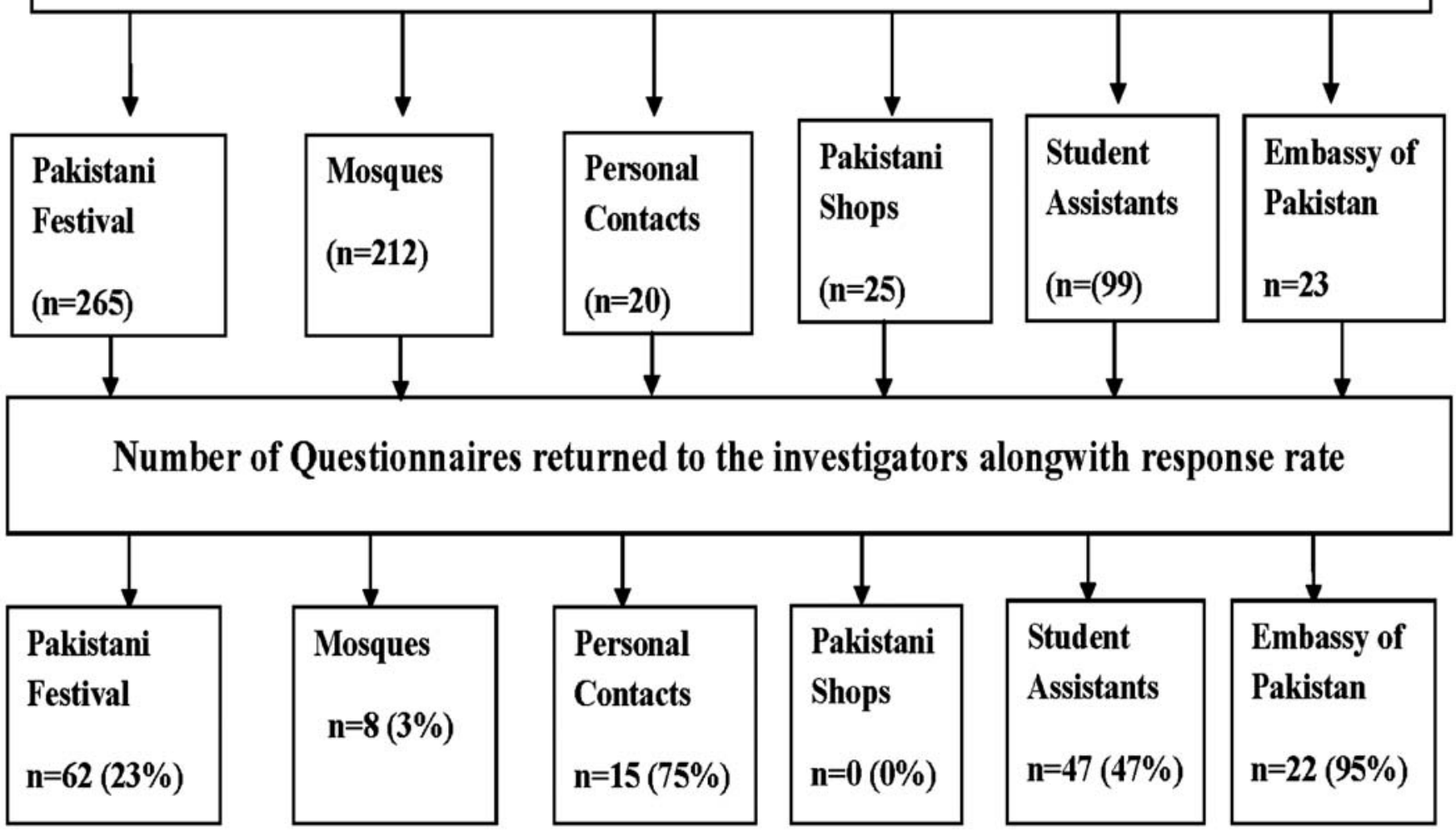

Figure-1: Flow sheet diagram for distribution and collection of the questionnaire. 
single item (good/very good versus fair/poor) while cardiovascular disease, diabetes, high blood pressure were measured as diagnosed clinically. Frequency of intake of dietary items (per day) was asked, while for fruit and vegetables, the usual amounts consumed were also asked. For assessment of change in dietary habits after migration; foods including fruits, vegetables, convenience foods, soft drinks/soda, dairy products, high fat/fried foods, deserts/candy/sweets, meat with food behaviours and patterns including baking/grilling foods, deep frying foods and restaurant meals/dining out were also analysed. The question was asked on 3-point scale; for food preparation methods. It consisted of categories, namely, much less often/no change/much more often while for foods, it consisted of categories eat much less/no change/eat much more.

In addition, data on socio-demographic variables including age, sex, marital status, highest finished educational level, living conditions or family structure ranging from living alone to living with parents, country of birth including mothers country of birth and fathers country of birth and Pakistani ethnicity were also collected.

Data was analysed with the help of SPSS version 20. Descriptive statistics including means and percentages were used to describe basic features and provide a summary of the collected data. Body mass index (BMI) was calculated as weight $(\mathrm{kg})$ divided by height $\left(\mathrm{cm}^{2}\right)$.

\section{Results}

There were a total of 154 Pakistanis who were asked to fill in the questionnaire for this study; 5 questionnaires had missing and irrelevant information, so they were not included in the analysis. In addition, there was missing data and reason could be the length of the questionnaire. The age range was 22-72 years. A large number of men and women were married. A significant proportion of the sample reported living in a household with children. Most of the men 110 (74.3\%) and women 39 (63.4\%) were born in Pakistan. The participants who identified themselves as Pakistanis were included in this study. Most of the participants were from Amsterdam, Rotterdam and The Hague, which are the largest cities in The Netherlands with average residence duration in the Netherlands of 25 years. The majority reported being Muslim. Among women, $10(25.9 \%)$ had either no education or less than primary education. The sample in this study predominantly consisted of Punjabi ethnicity.

Table-1 also describes self-reported anthropometric measures and general health status among immigrant Pakistanis living in The Netherlands. Overweight and
Table-1: Self-reported anthropometric measure, general health status and background characteristic of the Pakistani immigrants living in The Netherlands.

\begin{tabular}{|c|c|c|}
\hline Variable & $\begin{array}{c}\text { Men } \\
\text { (Total =92) } \\
\mathbf{n}(\%)\end{array}$ & $\begin{array}{c}\text { Women } \\
\text { (Total = 22) } \\
n(\%)\end{array}$ \\
\hline Overweight (BMI > 23 kg/m²) & 48 (43.8) & $7(17.6)$ \\
\hline Obesity (BMI > $\left.27.5 \mathrm{~kg} / \mathrm{m}^{2}\right)$ & $44(40.0)$ & $15(38.2)$ \\
\hline In general how would you say your health is & $\begin{array}{c}\text { Men } \\
(\text { Total =110) } \\
\mathbf{n}(\%)\end{array}$ & $\begin{array}{c}\text { Women } \\
\text { (Total = 37) } \\
n(\%)\end{array}$ \\
\hline Excellent & $26(23.9)$ & $10(26.8)$ \\
\hline Very Good & $23(21.2)$ & $9(24.4)$ \\
\hline Good & $39(35.4)$ & $8(22.0)$ \\
\hline Fair & $22(19.5)$ & $10(26.8)$ \\
\hline Prevalence of CVD and related risk factors & $\begin{array}{c}\text { Men } \\
\text { (Total =93) } \\
\mathbf{n}(\%)\end{array}$ & $\begin{array}{c}\text { Women } \\
\text { (Total = 18) } \\
\text { n (\%) }\end{array}$ \\
\hline Cardiovascular disease & $8(7.2)$ & Nil $^{*}$ \\
\hline Diabetes & $23(20.9)$ & $3(7.5)$ \\
\hline High Blood Pressure /Hypertension & $18(16.5)$ & $7(17.1)$ \\
\hline Hypercholesterolaemia & $16(14.4)$ & $7(17.5)$ \\
\hline Smoking & $28(27.0)$ & $1(2.5)$ \\
\hline Marital Status & $\begin{array}{c}\text { Men } \\
\text { (Total = 107) } \\
\mathbf{n}(\%)\end{array}$ & $\begin{array}{c}\text { Women } \\
\text { (Total = 39) } \\
n(\%)\end{array}$ \\
\hline Married/registered partnership & $78(72.5)$ & $27(68.4)$ \\
\hline Unmarried, have never been married & $24(22.0)$ & $9(23.7)$ \\
\hline Divorced or separated & $5(4.6)$ & $3(7.9)$ \\
\hline Country of birth & $\begin{array}{c}\text { Men } \\
\text { (Total = 110) } \\
\mathbf{n}(\%)\end{array}$ & $\begin{array}{c}\text { Women } \\
\text { (Total = 39) } \\
n(\%)\end{array}$ \\
\hline Pakistan & $82(74.3)$ & $25(63.4)$ \\
\hline The Netherlands & $21(19.5)$ & $13(34.1)$ \\
\hline Other & $7(7.2)$ & $1(2.4)$ \\
\hline Highest education level & $\begin{array}{c}\text { Men } \\
\text { (Total = 107) } \\
\mathbf{n}(\%)\end{array}$ & $\begin{array}{c}\text { Women } \\
\text { (Total = 38) } \\
\mathrm{n}(\%)\end{array}$ \\
\hline Primary or lower (5 years or less) & $7(6.7)$ & $10(25.9)$ \\
\hline Secondary Education (5-10 years) & $31(28.9)$ & $4(11.1)$ \\
\hline Higher secondary/College (10-14 years) & $41(37.8)$ & $11(29.6)$ \\
\hline University (> 14 years) & $28(25.6)$ & $13(33.3)$ \\
\hline
\end{tabular}

obesity prevalence was quite high in both men and women, though men reported higher prevalence of obesity than women. A significant proportion of women and men reported their health as being fair. Men reported higher prevalence of CVD 8 (7.2\%), while women reported no CVD. There was higher prevalence of diabetes among men $23(20.9 \%)$ as compared to women 3 (7.5\%). The prevalence of hypertension among women was the same as men; though prevalence of hypercholesterolemia was higher among women $7(17.5 \%)$ as compared to men 16 $(14.4 \%)$. Smoking was more prevalent in men as compared to women. 
Table-2: Daily intake of fruits and vegetables among Pakistani immigrants living in the Netherlands.

\begin{tabular}{|c|c|c|c|c|}
\hline Number of tablespoons of Vegetables (Total=152) n (\%) & $<1$ & $1-2$ & $3-4$ & $5-7$ \\
\hline Cooked/fried vegetables & $15(10.2)$ & $64(42.3)$ & $45(30.2)$ & $29(17.3)$ \\
\hline Lettuce/raw vegetables & $3523.1)$ & $54(35.3)$ & $31(20.7)$ & $32(20.9)$ \\
\hline Number of pieces of fruit (Total=152) n (\%) & $<1$ & $1-2$ & $3-4$ & $5-7$ \\
\hline \multicolumn{5}{|l|}{ Fruit $(n=150) \%$} \\
\hline Fruit & $13(9.0)$ & $77(50.5)$ & $41(26.9)$ & $21(13.6)$ \\
\hline Number of glasses of fruit juice & $<1$ & $1-2$ & $3-4$ & 5-7 \\
\hline Fruit Juice & $27(17.7)$ & $92(60.9)$ & $23(14.9)$ & $10(6.5)$ \\
\hline
\end{tabular}

1 Tablespoon $=14$ grams or $=15 \mathrm{ml}$.

1 Piece of fruit $=$ A mid-size apple or 2 mandarins $=100$ grams.

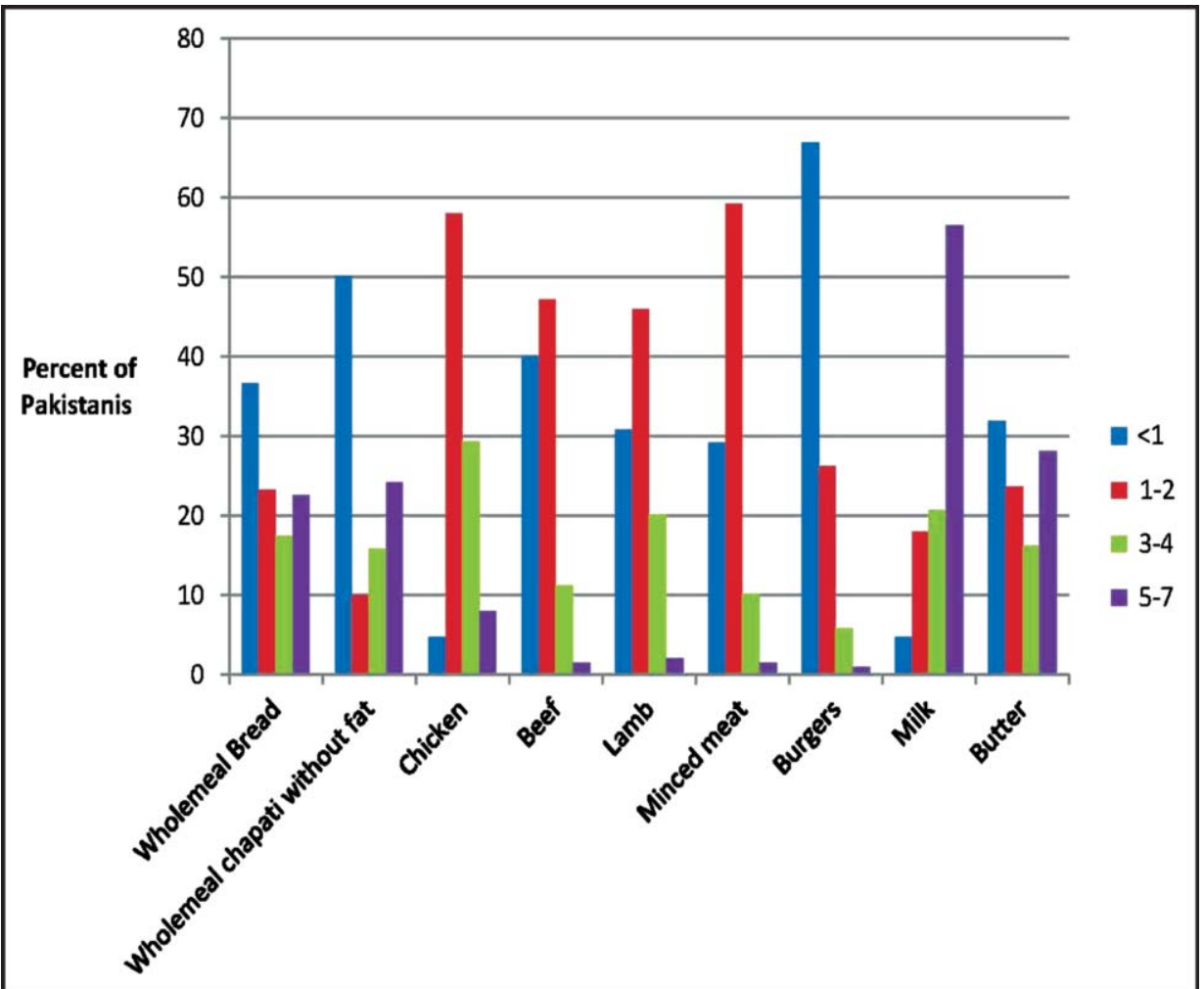

Figure-2: Consumption of cereals, meat and dairy products ranging from $<1$ day to 5-7 days in a week among Pakistani immigrants in The Netherlands.

In terms of fruits and vegetables, around half of the participants reported eating 100-200 grams of fruit daily (Table-2). There were $64(42.3 \%)$ participants who reported eating 50-100 grams of cooked/fried vegetables everyday while a smaller percentage $54(35.3 \%)$ reported eating 50-100 grams of raw vegetables daily. Many participants $92(60.9 \%)$ reported drinking $1-2$ glasses of fruit juice every day and 33 (21.4\%) participants also reported drinking more than 2 glasses of fruit juice every day (Table-2).

Figure-2 shows the intake of cereals, meat and dairy products, fish, tea with sugar and soft drinks with sugar. There were 33 (22.6\%) participants who reported use of wholemeal bread 5-7 days a week and $36(24.2 \%)$ reported use of traditional wholemeal chapatti (unleavened bread) without fat every day. Chicken appears to be the most commonly used meat with majority of the population 140 $(95.3 \%)$ eating it at least once per week. This is in contrast with consumption of lamb, beef or minced meat, where a large proportion reported eating these items less than once a week. Regarding dairy products, half of the participants reported drinking milk 5-7 days a week; also 42 (28.2\%) participants reported using butter (as a spread on bread) 5-7 days a week. For fish, $112(75.5 \%)$ participants reported eating it less than once a week. In all $89(60 \%)$ participants reported drinking tea with sugar and soft

Table-3a: Use of fat and oil by Pakistani immigrants living in the Netherlands.

$\begin{aligned} & \text { How many days per week do you use the following types of fat or oil } \\
& \text { (Total=86) } \mathbf{n}(\%)\end{aligned}$
\begin{tabular}{lcccc} 
& & & \\
Number of Days/week & $<1$ & $1-2$ & $3-4$ & $5-7$ \\
Butter/Margarine & $39(45.9)$ & $23(26.5)$ & $15(17.3)$ & $9(10.3)$ \\
Ghee & $62(72.1)$ & $13(15.1)$ & $5(5.8)$ & $6(7.0)$ \\
Number of Days/week & $<1$ & $1-2$ & $3-4$ & $5-7$ \\
Vegetable oil (n=144) & $11(12.5)$ & $8(9.0)$ & $13(14.6)$ & $57(66.9)$ \\
\hline
\end{tabular}


Table-3b: Cooking methods used by Pakistani immigrants living in the Netherlands.

How many days per week are the following cooking methods used in your house $(n=122) \%$

\begin{tabular}{lcccc}
\hline Number of Days/week & $<1$ & $1-2$ & $3-4$ & $5-7$ \\
Stir-frying/BBQ & $64(74.4)$ & $16(19.0)$ & $3(3.3)$ & $3(3.3)$ \\
Baking & $45(52.7)$ & $30(34.8)$ & $7(8.0)$ & $4(4.5)$ \\
Oven/Grilling/Roasting & $43(50.8)$ & $33(38.5)$ & $9(10.7)$ & Nil \\
Boiling & $42(48.7)$ & $33(38.3)$ & $10(11.2)$ & $1(0.9)$ \\
Steaming & $67(77.9)$ & $12(13.5)$ & $6(7.6)$ & $1(1.0)$ \\
Pressure Cooking & $42(48.8)$ & $21(24.0)$ & $15(17.8)$ & $9(10.4)$ \\
Deep frying food & $45(52.5)$ & $24(27.9)$ & $8(9.8)$ & $8(9.8)$ \\
Microwaving food & $57(66.4)$ & $16(19.3)$ & $5(5.9)$ & $7(8.4)$ \\
\hline
\end{tabular}

drinks with sugar 1-2 days a week; 25 (17\%) participants reported drinking tea with sugar and soft drinks with sugar 5-7 days a week.

Participants reported an increase in consumption of raw vegetables, cooked vegetables, convenience foods, fruits, soft drinks/soda, dairy products and white meat after migration to The Netherlands (Figure-3).

Similarly Pakistani immigrants reported decrease in intake of food items like high fat/fried foods, deserts/candy/ sweets, red meat and they also reported decrease in dining out after migration.
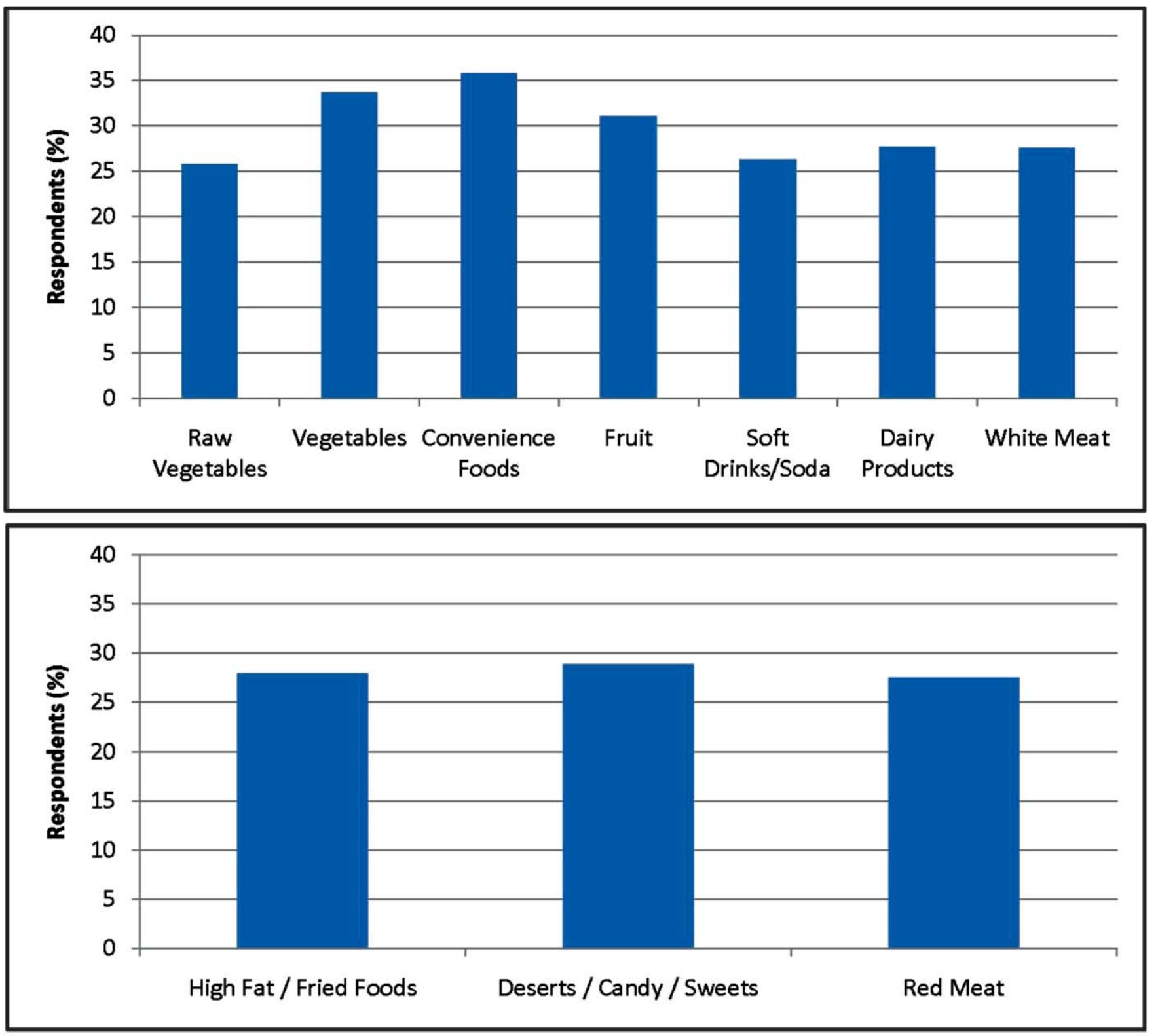

Figure-3: Changes in consumption of food items reported by more than $25 \%$ of participants as increased (above) or decreased (below) after migration. 
Table-3a describes the type of fat and oil and cooking methods used in the house. The majority of Pakistani immigrants 57 (67\%) reported using vegetable oil 5-7 days a week, while the use of ghee (clarified butter) was less frequent, $62(72.1 \%)$ reported using this less than once a week. Similarly use of margarine and butter in cooking (5-7 days a week) was only reported by $9(10.3 \%)$ participants. Table-3b shows that there were 135 (91\%) participants who reported that food was cooked daily in their home. In addition, Pakistanis reported decrease in baking, grilling and decrease in eating out/restaurant eating after migration from Pakistan to the Netherlands.

\section{Discussion}

The results in this study showed that half of the participants reported intake of fruits and vegetables every day, though portions eaten every day are quite less than recommended by World Health Organization. In addition, one third participants reported using wholemeal bread every day. Fruits, vegetables and whole grains have a protective effect against cardiovascular disease. ${ }^{24,25} \mathrm{~A}$ large number of participants also reported eating chicken or white meat in this study. A 20-year prospective study of 82,802 women found that high protein diet could lower the risk of heart disease ${ }^{26}$ and white meat is one of the major sources of animal protein. There's also substantial evidence that consumption of red meat is related to increased risk of coronary heart disease. 27,28 On the other hand, eating approximately one to two 3-ounce servings of fish a week reduces the risk of dying from heart disease by 36 percent. ${ }^{29}$

The participants in this study reported increased consumption of vegetables, convenient foods, fruits, soft drinks/soda, dairy products and white meat while at the same time reporting decreased intake of high fat/fried foods, deserts/candy/sweets and red meat after migration from Pakistan to The Netherlands. The participants also reported decrease in deep frying and dining out after migration.

According to the guidelines of World Health Organization, at least 400 grams of fruits and vegetables are recommended everyday. ${ }^{31}$ In the Netherlands, at least 2 portions of both fruits and vegetables should be consumed per day. 32 Our findings for intake of fruits and vegetables are comparable to a study from Amsterdam among local Dutch population ${ }^{33}$ where half of the Dutch population adhered to recommended amount of fruits while $35 \%$ adhered to recommended amount of vegetables. A large number of Pakistani immigrants reported intake of fruit juice every day. The greater consumption of fruit juice is associated with a higher risk of Type 2 diabetes and obesity. ${ }^{34}$

The results of this study showed that participants have typically changed from butter/ghee to vegetable oil, reduced consumption of sweets and increased consumption of white meat after migration. Regarding the cooking methods, Pakistani immigrants in this study reported increase in boiling foods after migration and at the same time reducing deep frying. These results are in line with results from a cross sectional study among Pakistani immigrants in Oslo. ${ }^{35}$ The participants in this study reported increased use of dairy products and convenience foods after migration, which is a source of fat. The study from inner city Manchester reported that Pakistani men and women had the highest percentage of energy from fat. ${ }^{36}$ The aforementioned changes in dietary habits could also be seen among other non-western immigrants: a study among Chinese immigrants in Canada ${ }^{37}$ has shown an increase in consumption of white meat, convenience foods and reduction in deep frying. Pakistanis living in Netherlands who participated in this study also reported less frequent use of fish, with $76 \%$ reported using fish less than once a week.

In this study, Pakistani immigrants showed significant changes in dietary habits, both favourable and unfavourable, being associated with risk of cardiovascular diseases among immigrant Pakistanis living in The Netherlands including use of soft drinks and use of sugar in tea and coffee. The soft drinks increase the risk for developing Type 2 diabetes. ${ }^{28}$ It must be noted that the traditional Pakistani beverages consist of lassi (milk with yogurt), lemonade, green tea and certain kind of sweet juices and does not include soft drinks. A study among students of a private medical college in Pakistan showed that nearly $97 \%$ reported consumption of junk food, while $60 \%$ reported use of whole grain food in their diet. ${ }^{31}$

\section{Limitations}

Self Reporting, Low response rate and overrepresentation of men are some of the limitations of this study. As has been shown by other researchers, accessing South Asian communities is difficult, and is an impediment to research. 30

\section{Conclusion}

This study was the first of its kind to investigate the food intake, dietary pattern and dietary habits related to risk of cardiovascular disease among Pakistani immigrants in the Netherlands.

Disclaimer: This manuscript is part of the $\mathrm{PhD}$ thesis of $\mathrm{Dr}$ Qaisar Raza. 
Competing Interests: The authors declare no competing interests. The authors are not involved with any financial or non-financial interests related to publication of this study.

Funding Sources: The authors acknowledge help for funding from Higher Education Commission of Pakistan and the Free University, Amsterdam, The Netherlands. The funding sources had no involvement in the study design, data collection, data analysis and interpretation of data. They also had no involvement, whatsoever, in writing of the article and in the decision to submit the article for publication.

\section{References}

1. Oladele CR, Pathak EB, Yang J, Nembhard WN, Sharma S, Himmelgreen $D$, et al. Acculturation and dietary intake pattern among Jamaican immigrants in the US. Prev Med Rep. 2017;9:805.

2. Marian L, Neuhouser RD, Thompson B, Coronado GD, Cam C, Soloman MS. Higher Fat Intake and Lower Fruit and Vegetables Intakes Are Associated with Greater Acculturation Among Mexicans Living in Washington State. J Am Diet Assoc. 2004;104:51-7.

3. Balarajan R. Ethnicity and variations in the nation's health. Health Trends. 1995;27:114-9.

4. Engelgau M, El-Saharty $S$, Kudesia $P$, Rajan V, Rosenhouse $S$, Okamoto K. Capitalizing on the Demographic Transition: Tackling Noncommunicable Diseases in South Asia. Washington DC: The World Bank, 2011.

5. $\mathrm{Ng} \mathrm{M}$, Fleming $\mathrm{T}$, Robinson $\mathrm{M}$ et al. Global, regional, and national prevalence of overweight and obesity in children and adults during 1980-2013: a systematic analysis for the Global Burden of Disease Study 2013. Lancet. $2014 ; 384: 766-81$.

6. Chaturvedi $\mathrm{N}$, Fuller $\mathrm{JH}$. Ethnic differences in mortality from cardiovascular disease in the UK: do they persist in people with diabetes?. J Epidemiol Community Health. 1996; 50:137-9.

7. Yusuf S, Reddy S, Ounpuu S, Anand S. Global burden of cardiovascular diseases: Part 11: variations in cardiovascular disease by specific ethnic groups and geographic regions and prevention strategies. Circulation. 2001;104:2855-64.

8. Holmboe-Ottesen G, Wandel M. Changes in dietary habits after migration and consequences for health: a focus on South Asians in Europe. Food Nutr Res. 2012;56.

9. LeCroy MN, Stevens J. Dietary intake and habits of South Asian immigrants living in Western countries. Nutr Rev. 2017;75:391404.

10. Nishtar S. Health Indicators of Pakistan - Gateway Paper II. Islamabad, Pakistan: Heartfile;2007.

11. Anjum Q, Omair A, Ahmed Y, Shaikh S, Usman J, Qureshi F. Frequency of Food Items among Households in a Low Socioeconomic Area of Karachi. J Pak Med Assoc. 2008;54;580.

12. Sultana B, Anwar F, lqbalS. Effect of different cooking methods on the antioxidant activity of some vegetables from Pakistan. Intl J Food Sci Technol. 2008;43:560-7.

13. Wandel M, Kumar MRB, Holmboe-Ottesen G. Changes in food habits after migration among South Asians settled in Oslo: The effect of demographic, socio-economic and integration factors. Appetite. 2008;50:376-85.

14. Mellin-Olsen T Wandel M. Changes in Food Habits among Pakistani Immigrant Women in Oslo, Norway. Ethnicity and Health. 2005;10:311-39.
15. Staistics Netherlands -CBS. [online]2013[cited 2013 Oct 8] Available from: URL:(http://www.cbs.nl/en$\mathrm{GB} /$ menu/home/default.htm?Languageswitch=on)

16. Wikipedia. Pakistani Americans. [online]2013[cited 2013 Oct 8].

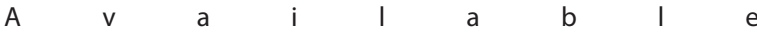
from:URL:http://en.wikipedia.org/wiki/Pakistani_American.

17. Nicolaou M, Doak CM, Dam RVM Brug J, Stronks K, Seidell JC. Cultural and Social Influences on Food Consumption in Dutch Residents of Turkish and Moroccan Origin: A Qaulatitative study. J Nutr Educ Behaviour. 2009;41:232-41.

18. Nicolaou M, Dam RVM, Stronks K. Ethnicity, Acculturation and Education Level in Relation to Quality of the Diet: a study of Surinamese residents of the Netherlands. J Human Nutr Dietetics. 2006;19:383-93.

19. Bhopal R, Unwin N, White M, Yallop J, Walker L, Alberti KG, etal. Heterogeneity of coronary heart disease risk factors in Indian, Pakistani, Bangladeshi, and European origin populations: cross sectional study. BMJ. 1999;319:215.

20. Charan J, Biswas T. How to calculate sample size for different study designs in medical research? Indian J Psychol Med. 2013;35:121-6.

21. VU University Medical Centre A. No Human Subjects directly involved Amsterdam [cited 29-10-2013]. (http://www.vumc.com/branch/researchguide/ldeasPreparation/ 7271116/7271137/).Wet bescherming persoonsgegevens. [cited 2015 03.12.2015]. Availablefrom: (http://www.privacy.nl/uploads/guide_for_controller_ministry_j ustice.pdf) NOT FOUND

22. (AGM) Eindraport Amsterdamse Gezondheids Monitor (AGM) 2008. Zo gezond is Amsterdam. [online]2013[cited 2013 Oct 29]. Available from:URL:http://kic.nisb.nl/site/catalogus/show/10604

23. Raza Q, Nicolaou M, Dijkshoorn H, Seidell J. Comparison of general health status, cardiovascular disease, diabetes and fruit and vegetable intake between the immigrant Pakistani population in The Netherlands and the local Amsterdam population. ETHNICITY \& HEALTH, 2017;22:551-64.

24. Agudo A. Measuring intake of fruit and vegetables. Proceedings from a workshop on Fruit and Vegetables for Health by World Health Organization/Food and Agriculture organization: 1-3 September 2004; Japan.

25. Wallace TC, Bailey RL, Blumberg JB, Freeman BB, C, Chen O, Kristi $M$, etal. Fruits, vegetables, and health: A comprehensive narrative, umbrella review of the science and recommendations for enhanced public policy to improve intake. Crit Rev Food Sci Nutr 2019;60:2174-211

26. Mellen PB, Walsh TF, Herrington DM. Whole grain intake and cardiovascular disease: A meta-analysis. Nutr Metab Cardiovasc Dis 2008; 18:283-90.

27. Halton TL, Willet WC, Liu S, Manson JE, Albert CM, Rexrode K, etal Low-carbohydrate-diet score and the risk of coronary heart disease in women. N Engl J Med. 2006;355:1991-2002.

28. Bernstein AM, Sun Q, Hu FB, Stampfer MJ, Manson JE, Willet WC. Major dietary protein sources and risk of coronary heart disease in women. Circulation. 2010;122:876-83.

29. Mozaffarian D, Rimm EB. Fish intake, contaminants, and human health: evaluating the risks and the benefits. J Am Med Assoc. 2006;296:1885-99.

30. Rankin J, Bhopal R. Understanding of heart disease and diabetes in a South Asian community: cross-sectional study testing the 'snowball' sample method. Public Health. 2001; 115:253-60.

31. World Health Organization. Joint WHO/FAO expert consultation on diet, nutrition and the prevention of chronic diseases. WHO technical report series. 2003;916.

32. (AGM) Eindraport Amsterdamse Gezondheids Monitor. Zo gezond is Amsterdam. [online]2013[cited 2013 Oct 8]. Available 
from:URL (http://kic.nisb.nl/site/catalogus/show/10604)

33. Dutch National Food Consumption Survey 2007-2010 : Diet of children and adults aged 7 to 69 years. [online]2013[cited 2013

Oct 29].

Available

from:URL

(https://rivm.openrepository.com/handle/10029/261553)

34. Muraki I, Imamura F, Manson JE, Hu FB, Willett WC, Dam RMV, etal. Fruit consumption and risk of type 2 diabetes: results from three prospective longitudinal cohort studies. BMJ. 2013;347:f5001.

35. Holmboe-Ottesen G, Raberg MK, Natland ST, Kumar BN, Wandel M. Dietary patterns among South Asian immigrants in Oslo: Implications for preventive measures. Public Health Nutrition. 2006;9:66.

36. Vyas A, Greenhalgh A, Sangera B, Riste L, Sharma S, Cruickshank K.
Nutrient intakes of an adult Pakistani, European and African Caribbean community in inner city Britain. J Human Nutr Dietetics. 2003;16:327-37.

37. Rosenmöller DL, Gasevic D, Seidell J, Lear SA. Determinants of changes in dietary patterns among Chinese immigrants: a crosssectional analysis. Int J Behav Nutr Phys Act 2011;8:42.

38. Bray GA, Popkin B. Dietary sugar and body weight: have we reached a crisis in the epidemic of obesity and diabetes?: health be damned! Pour on the sugar. Diabetes Care. 2014;37:950-6.

39. Rankin J, Bhopal R. Understanding of heart disease and diabetes in a South Asian community: cross-sectional study testing the 'snowball' sample method. Public Health. 2001; 115:253-60. 